\title{
Immune reconstitution from peripheral blood mononuclear cells inhibits lung carcinoma growth in NOD/SCID mice
}

\author{
XIANG LIU ${ }^{1,2 *}$, HUILING LI ${ }^{2,3 *}$, JUN LIU ${ }^{2}$, YUBAO GUAN ${ }^{4}$, LIYAN HUANG $^{2}$, \\ HAILING TANG ${ }^{2}$ and JIANXING HE ${ }^{2}$ \\ ${ }^{1}$ Department of Cardiothoracic Surgery, The Second Hospital Affiliated to University of South China, Hengyang, \\ Hunan 421001; ${ }^{2}$ Department of Cardiothoracic Surgery, Guangzhou Institute of Respiratory Disease, \\ State Key Laboratory of Respiratory Disease, The First Affiliated Hospital of Guangzhou Medical College, \\ Guangzhou, Guangdong 510120; ${ }^{3}$ Department of Respiratory Medicine, Hainan Branch of Chinese PLA \\ General Hospital, Sanya, Hainan 572000; ${ }^{4}$ Department of Radiology, Guangzhou Institute of Respiratory Disease, \\ State Key Laboratory of Respiratory Disease, The First Affiliated Hospital of Guangzhou \\ Medical College, Guangzhou, Guangdong 510120, P.R. China
}

Received January 13, 2014; Accepted June 19, 2014

DOI: $10.3892 / 01.2014 .2379$

\begin{abstract}
Drug resistance and immune deficiency are important factors for the poor prognosis of lung carcinoma. The present study explored the possible protective effect of immune reconstitution from peripheral blood mononuclear cells (PBMCs) on multi-drug-resistant human lung carcinoma Am1010 cells in non-obese diabetic/severe combined immunodeficient (NOD/SCID) mice. The inoculated tumor fragments grew rapidly in the NOD/SCID mice. The growth was significantly inhibited by intraperitoneal injection of PBMCs. In the mice injected with PBMCs, numerous $\mathrm{CD}^{+}$ and $\mathrm{CD} 8^{+}$cells, but less $\mathrm{CD} 4^{+}$cells, were found in spleen and tumor tissues. These data suggest that PBMC transplantation inhibits lung carcinoma progression via the reconstitution of the immune system, particularly of cytotoxic T lymphocytes.
\end{abstract}

\section{Introduction}

Lung cancer is the leading cause of cancer-related mortality worldwide (1). Numerous achievements have been made in chemotherapy, radiotherapy and surgical techniques. However, the survival rate has not been improved for many decades.

Correspondence to: Dr Jianxing He, Department of Cardiothoracic Surgery, Guangzhou Institute of Respiratory Disease, State Key Laboratory of Respiratory Disease, The First Affiliated Hospital of Guangzhou Medical College, 151 Yanjiang Road, Guangzhou, Guangdong 510120, P.R. China

E-mail: jianxinghe@yeah.net

*Contributed equally

Key words: NOD/SCID, T lymphocytes, peripheral blood mononuclear cells, lung carcinoma, Am1010
This poor prognosis is mostly due to the development of drug resistance by cancer cells during treatment and the likelihood of subsequent metastasis (2). The drug-surviving cells (DSCs) are responsible for tumor regeneration after chemotherapy, and may be one of the mechanisms involved in drug resistance (3). Immunoresistance induced by chemotherapy agents may be another mechanism (4). Am1010, a new DSC line, was established in our previous study from an arm muscle metastasic tumor of a patient diagnosed with lung adenocarcinoma (5). The Am1010 cell line demonstrated in vitro multi-drug-resistance against cisplatin, taxol and geitinib, as well as in vivo invasion ability (5).

Chemotherapy of lung cancer is targeted not only at the tumor cells but also at the immune system. The immune system is a key factor in preventing the development of tumors and in limiting tumor growth (6). Tumor infiltration of lymphocytes is frequently found in tumors, suggesting that tumors trigger an immune response in the host. A number of studies have reported a survival benefit associated with the presence of tumor-infiltrating lymphocytes (TILs) (7-9); although, in some circumstances, it was a paradoxical result $(10,11)$.

Non-obese diabetic/severe combined immunodeficient (NOD/SCID) mice have multiple defects in innate and adaptive immunologic functions (12). They are absent of $\mathrm{T}$ and $\mathrm{B}$ lymphocytes and natural killer (NK) cells. They also exhibit dysfunctional macrophages, dendritic cells and complement systems. Thus, NOD/SCID mice are an ideal tool for immunodeficient studies. These mice are also commonly used in studies involving various types of cancer xenografts $(13,14)$. Previously, intravenous injection of granulocyte colony-stimulating factor-induced white blood cells from human peripheral blood into NOD/SCID mice was shown to produce a 6.5 -month detection of human T lymphocytes (15). Peripheral blood mononuclear cell (PBMC) injection was reported to inhibit the growth of various types of tumors in NOD/SCID mice, including Burkitt's 
lymphoma (16) and neuroblastoma cells (17). However, the protective role of PBMCs in lung cancer is not yet known to date.

In the present study, NOD/SCID mice were inoculated with lung carcinoma fragments (obtained by injecting Am1010 cells into NOD/SCID mice, allowing the tumors to grow to $150 \mathrm{~mm}^{3}$ and then cutting the tumors into equally sized fragments) and human PBMCs. An ideal heterotopic lung cancer model was thus established. Using the model, we observed the protective effect of PBMCs on tumor growth and the reconstitution of immune system.

\section{Materials and methods}

Reagents. Matrigel and FACS lysing solution were purchased from BD Biosciences (San Jose, CA, USA). Hydrogen peroxide $\left(\mathrm{H}_{2} \mathrm{O}_{2}\right), 3,3$ '-diaminobenzidine and pentobarbital sodium were purchased from Sigma-Aldrich (St. Louis, MO, USA). RIPA lysis buffer and enhanced chemiluminescence (ECL) reagent were purchased from Pierce Biotechnology, Inc. (Rockford, IL, USA). Rabbit polyclonal antibody against PC5-CD3 was purchased from Beckman Coulter, Inc. (Brea, CA, USA). Rabbit monoclonal antibody against CD3 (ab109531), and rabbit polyclonal antibodies against CD4 (ab70951), CD8 (ab85792) and FoxP3 (ab10563) were purchased from Abcam (Cambridge, MA, USA). Rabbit polyclonal antibody against GAPDH was purchased from Cell Signaling Technology, Inc. (Danvers, MA, USA). Horseradish peroxidase (HRP)-coupled goat polyclonal anti-rabbit secondary $\operatorname{IgG}(\mathrm{sc}-2004)$ and biotinylated goat polyclonal anti-rabbit IgG (sc-2040) secondary antibodies, as well as the avidin-biotin-HRP complex were purchased from Santa Cruz Biotechnology, Inc. (Dallas, TX, USA). RPMI-1640 medium and fetal bovine serum (FBS) were purchased from Life Technologies (Grand Island, NY, USA).

Animals.MaleNOD/SCID mice were provided by Experimental Animal Center, Sun Yat-Sen University (Guangzhou, China). The mice were kept in separate cages in a room with specific pathogen-free standards at a constant humidity and temperature, with food and water available ad libitum. The animal room was on a 12/12-h light/dark cycle. At the age of 4 weeks, blood samples were taken from the tail vein for determination of immunoglobulin (Ig) levels. Only the mice with IgM levels $<1 \mu \mathrm{g} / \mathrm{ml}$ were used for further study. The experiments were performed at the 6 th week. Tumor fragments were obtained by injecting Am1010 cells into six NOD/SCID mice, allowing the tumors to grow to $150 \mathrm{~mm}^{3}$ and then cutting the tumors into equally sized fragments. For the inoculation with tumor fragments and/or PBMCs, the mice were divided randomly into three groups. The Am1010+PBMC group was inoculated with a tumor fragment and PBMCs $(n=10)$; the Am1010 group was inoculated with a tumor fragment $(n=10)$; and the PBMC group was only injected with PBMCs $(n=5)$. This study was approved by Guangzhou Medical College (Guangzhou, China).

Establishment of xenografts. The green fluorescent protein (GFP)-Am1010 cell line was established in our previous study (5). The cells were stored in liquid nitrogen until use. A total of $2 \times 10^{7}$ cells in a $200 \mu 1$ volume of $50 \%$ Matrigel were injected subcutaneously into the dorsal surface of the right lower quadrant of the six NOD/SCID mice. Tumor growth was assessed by palpation every 3 days. The two bisecting diameters were measured with calipers, and the volume was calculated using the formula $0.4 \mathrm{x} a b^{2}$, where $a$ represents the longer diameter and $b$ the shorter perpendicular diameter (18). When the tumors grew up to a size of $150 \mathrm{~mm}^{3}$, they were removed and cut into $1 \times 3 \times 3 \mathrm{~mm}$ fragments. Twenty recipient mice were anesthetized with pentobarbital sodium $(10 \mathrm{mg} / \mathrm{kg})$. A 3-mm skin incision was cut at the sixth rib, left midaxillary line. A fragment of tumor was put into the incision, and the incision was sutured. The five other mice in the PBMC group underwent the same surgical procedure, but without insertion of a tumor fragment.

Human PBMC preparation and transplantation. On the day of inoculation with tumor segments, human PBMCs were prepared according to a previous study (19). Fresh peripheral venous blood from healthy adult volunteers was collected at The First Affiliated Hospital of Guangzhou Medical College (Guangzhou, China) in heparinized tubes. For the isolation of PBMCs, leucosep tubes (Greiner Bio-One, Wemmel, Belgium) were used, and blood was diluted 1:1 with RPMI-1640 medium (vol/vol) prior to transferring into the leucosep tube. Following centrifugation $(10 \mathrm{~min}$, $1000 \mathrm{x}$ g), the PBMC layer was pooled and transferred into a $15-\mathrm{ml}$ falcon tube. The sample was washed with $10 \mathrm{ml}$ phosphate-buffered saline (PBS) and centrifuged again for $10 \mathrm{~min}$ at $250 \mathrm{x} \mathrm{g}$. The obtained cell pellet was resuspended in PBS. A total of $1 \times 10^{8} \mathrm{PBMCs}$ per mouse were intraperitoneally injected into NOD/SCID mice of the Am1010+PBMC and PBMC groups, for the reconstitution of immune system. The same volume of PBS was injected into the mice of the Am1010 group.

Flow cytometry. To examine reconstitution of the immune system due to $\mathrm{PBMC}$ transplantation in the recipient NOD/SCID mice, $\mathrm{CD}^{+}$cells were analyzed by flow cytometry. In brief, peripheral blood $(100 \mu \mathrm{l})$ was collected into EDTA-coated tubes from the tail vein at every week following the transplantation for four weeks. Red blood cells were first lysed with FACS lysing solution and then washed twice with PBS containing 2\% FBS. The leukocytes were then incubated with PC5-labeled anti-CD3 antibody for $30 \mathrm{~min}$ at $4^{\circ} \mathrm{C}$. The staining was assessed by flow cytometry. PBMCs obtained from normal human volunteers and normal mice were used as positive and negative controls, respectively. Results are expressed as the percentage of positive cells gated in the human lymphocyte population in the scatter plot.

Whole-body fluorescence imaging. Whole-body fluorescence imaging was performed to examine the growth of the inoculated tumor fragment every seven days. The mice were anesthetized with $1 \%$ pentobarbital sodium $(0.2 \mathrm{ml} / 20 \mathrm{~g}$ body weight), and were placed in a NightOWLII LB 983 molecular light imager (Berthold Technologies, Bad Wildbad, Germany). The images were photographed for 1 sec using a GFP filter (GFP Ex480/20 and Em520/10; Berthold Technologies). Data were processed with WinLight software (Winlight System, Pertuis, France) and the fluorescent area was recorded. 
A

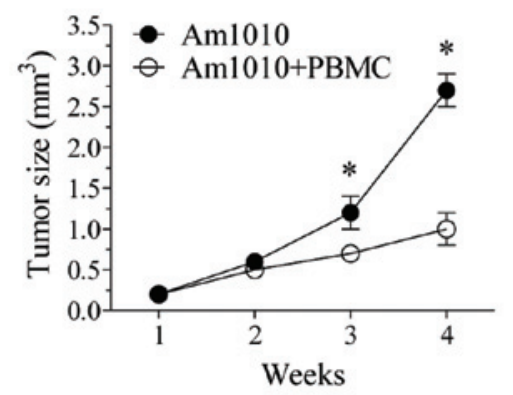

C

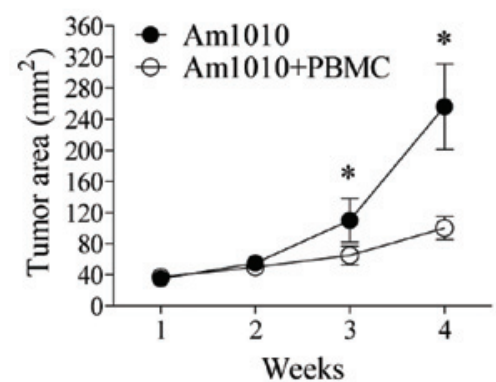

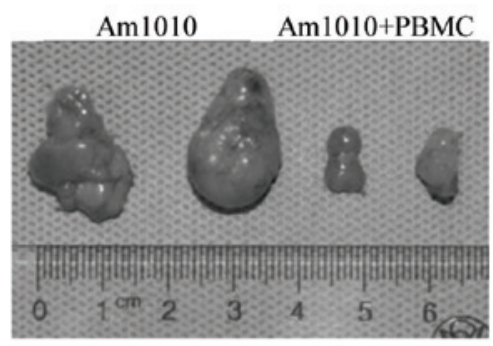

D

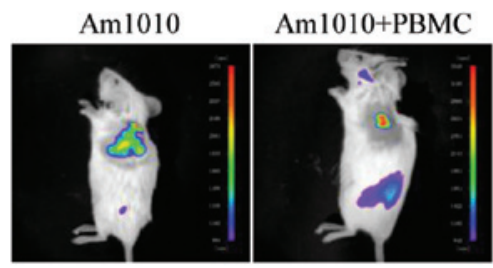

Figure 1. Tumor growth was observed after tumor segments were inoculated into the SCID/NOD mice, which were injected intraperitoneally human PBMCs or not. (A) The tumor growth curve by palpation, (B) tumors at the fourth week after inoculation, (C) the tumor area by fluorescence imaging and (D) tumor fluorescence imaging after inoculation. ${ }^{*} \mathrm{P}<0.05$, vs. the AM1010+PBMC group. SCID/NOD, non-obese diabetic/severe combined immunodeficient; PBMCs, peripheral blood mononuclear cells.

Histological examination and immunohistochemistry. At four weeks frollowing tumor fragment and/or PBMC administration, all mice were anesthetized with $10 \%$ chloral hydrate and perfused intracardially with normal saline and $4 \%$ paraformaldehyde in $0.1 \mathrm{M}$ phosphate buffer $(\mathrm{pH} 7.4)$. The spleens and tumors were fixed in $10 \%$ formalin solution, embedded in paraffin and cut serially into $4-\mu \mathrm{m}$ sections. Some of the sections were stained with hematoxylin and eosin (H\&E), while others were used for immunohistochemistry.

Immunohistochemistry was performed to detect CD3, CD4, CD8 and FoxP3 expression according to a previous study (20). Briefly, endogenous peroxidase was first quenched with $0.3 \% \mathrm{H}_{2} \mathrm{O}_{2}$. Prior to the application of primary antibody, nonspecific binding was blocked with normal non-immune serum, and tissue sections were incubated with primary antibody (1:500 each) at $4^{\circ} \mathrm{C}$ overnight. Sections were then incubated with biotinylated secondary antibody (1:200) for $2 \mathrm{~h}$ at room temperature, followed by avidin-biotin-HRP complex (1:150) for $1 \mathrm{~h}$. Immunohistochemical reactions were revealed by using $0.05 \%$ 3,3'-diaminobenzidine and $0.03 \%$ $\mathrm{H}_{2} \mathrm{O}_{2}$ as chromogen. Following each incubation, sections were thoroughly washed with PBS. Negative controls were performed by omitting the primary antibody, and showed no positive staining.

Western blotting. Total tissue proteins were extracted with RIPA lysis buffer, quantified using the Bradford method and separated by SDS-PAGE (12\%). A total of $40 \mu \mathrm{g}$ of protein was used to test for CD3, CD4, CD8 and FoxP3. Proteins were transferred to polyvinylidene fluoride membranes (Millipore, Billerica, MA, USA), and membranes were

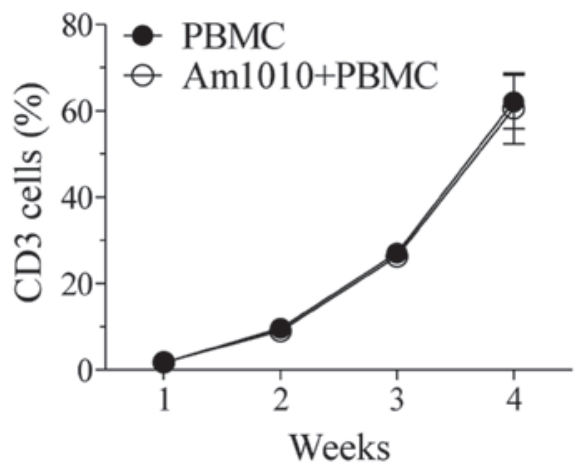

Figure 2. T lymphocytes in the peripheral blood. T-lymphocyte marker CD3 was measured with flow cytometry in PBMC-injected mice of the PBMC and AM1010+PBMC groups. The percentages of $\mathrm{CD}^{+}$cells among total nucleated cells are shown. SCID/NOD, non-obese diabetic/severe combined immunodeficient; PBMCs, peripheral blood mononuclear cells.

incubated overnight at $4^{\circ} \mathrm{C}$ with antibody against CD3, CD4, CD8, FoxP3 (1:1000 each) or GAPDH (1:10,000). The membranes were incubated with HRP-coupled secondary IgG for $1 \mathrm{~h}$. The bound proteins were then visualized using ECL and analyzed using BioImaging Systems (UVP, Upland, CA, USA).

Statistics. Data are presented as the mean \pm standard error of the mean. Statistical analysis was performed using one-way analysis of variance followed by Dunnett's test for multiple comparisons. $\mathrm{P}<0.05$ was considered to indicate a statistically significant difference. 
A
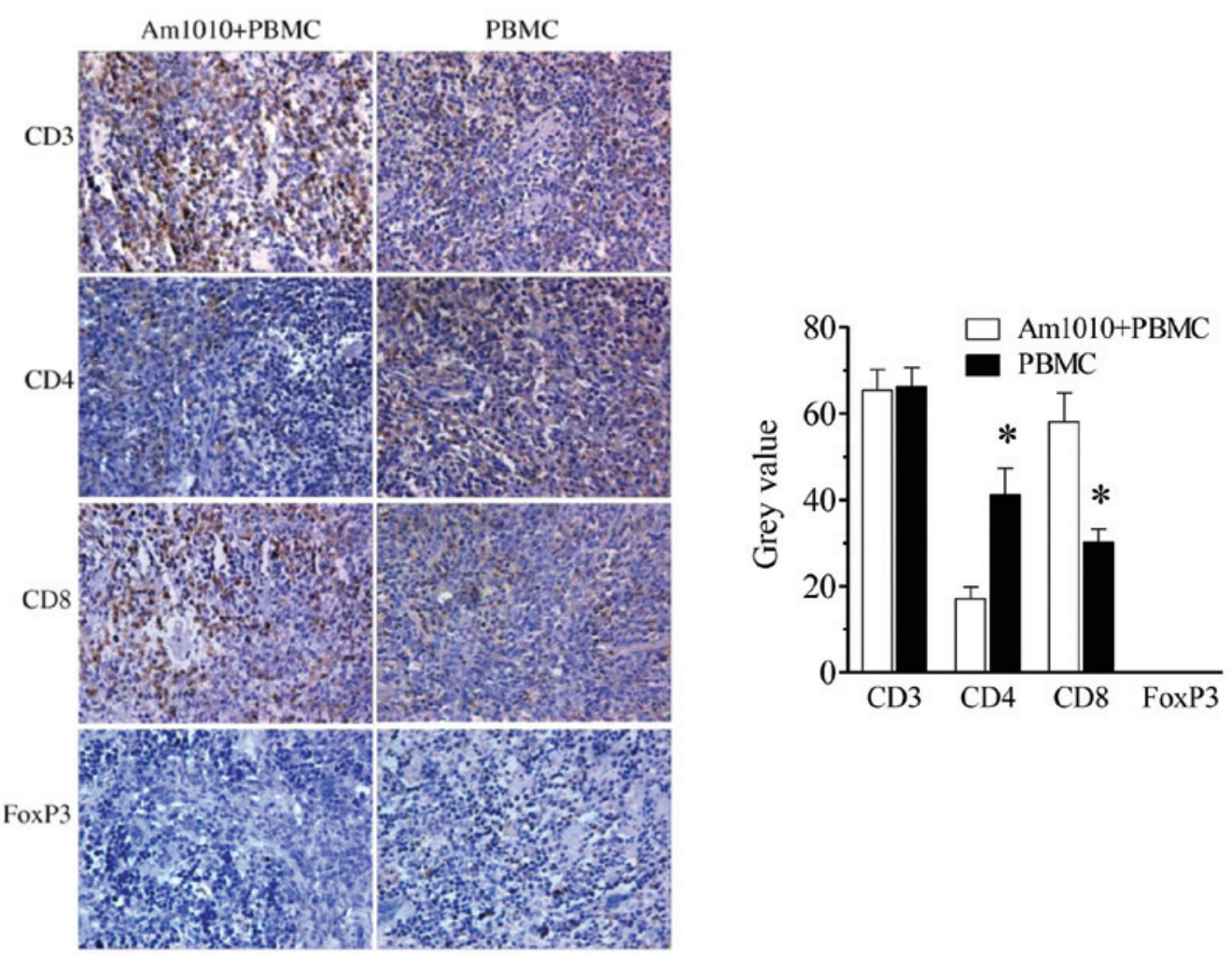

B
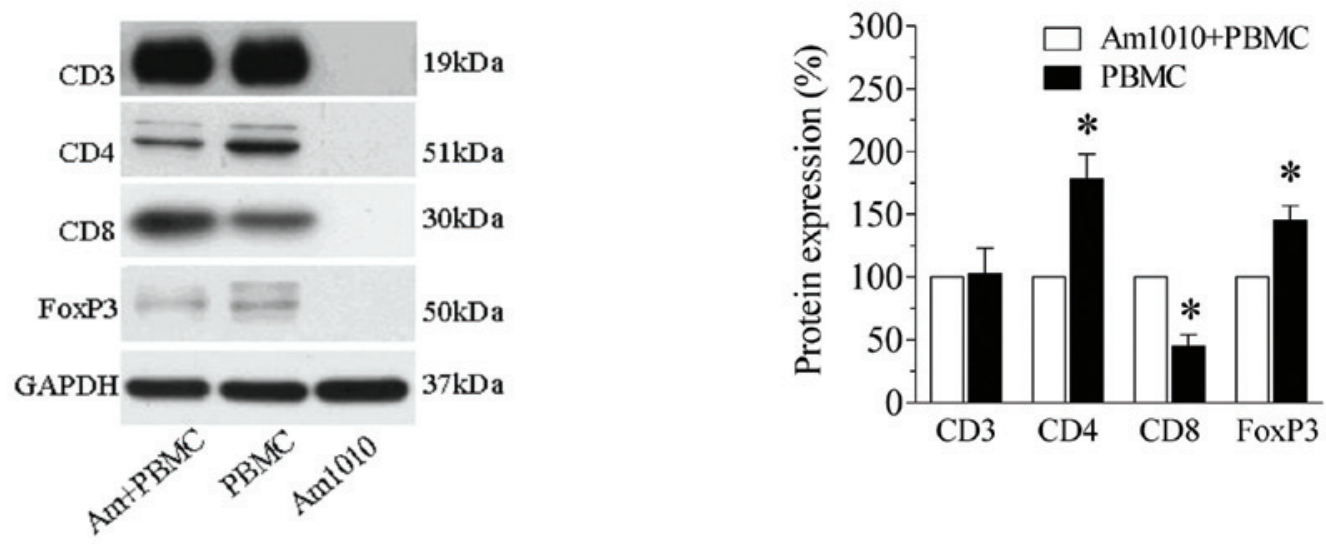

Figure 3. Recruitment of $\mathrm{T}$ lymphocytes in the spleen. The spleens were removed after four weeks of tumor segment inoculation and/or PBMC injection. The positive cells and expression levels of CD3, CD4, CD8 and FoxP3 were examined by (A) immunohistochemistry (magnification, x200) and (B) western blotting. The gray value was shown. "P<0.05, vs. the AM1010+PBMC group. PBMC, peripheral blood mononuclear cell.

\section{Results}

PBMC transplantation inhibited tumor growth. The inoculation of tumor segments produced $100 \%$ tumor growth in the NOD/SCID mice in the Am1010 and Am1010+PBMC groups. The tumor size increased with time (Fig. 1A), and when comparing tumor growth in the two groups, it was faster in the Am1010 group compared with the Am1010+PBMC group. The difference in tumor size between the two groups became significant from the third week after inoculation $(\mathrm{P}<0.05)($ Fig. 1A,B).
We further examined the tumor growth with fluorescence imaging in the Am1010 and Am1010+PBMC groups. Under fluorescence imaging, the GFP protein of the tumors was expressed stably. The tumors appeared green-yellow at the inoculation sites (Fig. 1D). The fluorescence area in the two groups increased with time (Fig. 1C). It was significantly larger in the Am1010 group than in the Am1010+PBMC group at the third and fourth week $(\mathrm{P}<0.05$, Fig. 1C,D). These results showed that PBMC transplantation exhibited a marked inhibitory effect on tumor growth. 
A

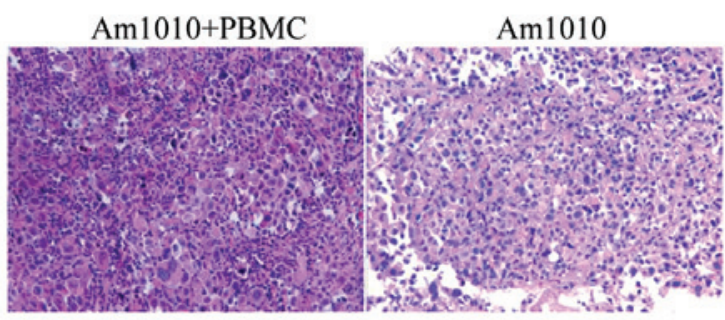

B

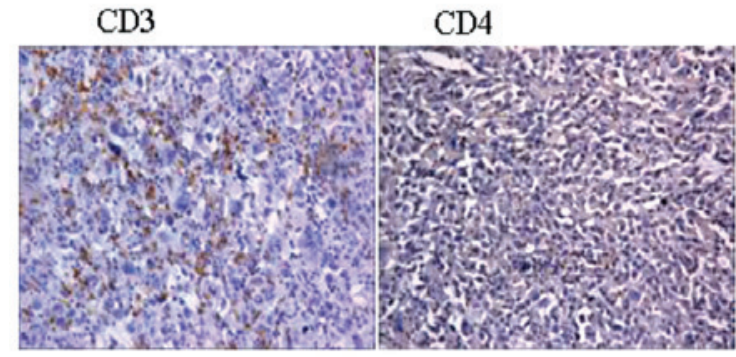

CD8

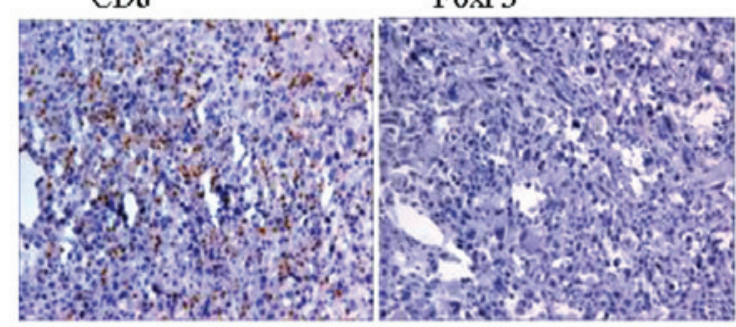

C

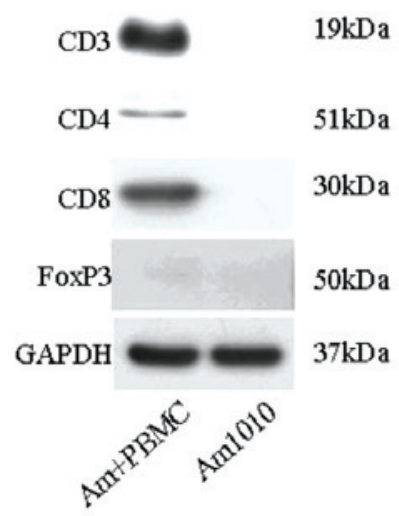

Figure 4. Recruitment of T lymphocytes in tumors. The tumors were removed after four weeks of tumor segment inoculation. (A) The tumor infiltrating cells were tested with hematoxylin and eosin staining (magnification, x200). The positive cells and expression levels of CD3, CD4, CD8 and FoxP3 were examined by (B) immunohistochemistry (magnification, x200) and (C) western blotting. PBMC, peripheral blood mononuclear cell.

T-lymphocyte reconstitution in the peripheral blood. SCID/NOD mice are absent from $\mathrm{T}$ and $\mathrm{B}$ lymphocytes and NK cells. Previously, it has been shown that PBMC transplantation can reconstitute the immune system (15). To confirm this, we tested T-lymphocyte marker CD3 in the peripheral blood with flow cytometry. $\mathrm{CD}^{+}$cells were detected early at the first week after PBMC injection in the PBMC and Am1010+PBMC groups (Fig. 2). The ratio of $\mathrm{CD}^{+}$cells to normal human nucleated cells was more than $1 \%$ at the 1 st week, and increased with time. The increase/trend was similar between the two groups. At the fourth week, the ratio of $\mathrm{CD}^{+}$cells was increased to $70 \%$. Thus, the T-lymphocyte reconstitution was successfully carried out in this study.
T-lymphocyte recruitment in the spleen. To further examine the reconstitution of the immune system, we examined T-lymphocyte recruitment in the spleen at the fourth week following PBMC transplantation using immunohistochemistry (Fig. 3A). Numerous $\mathrm{CD}^{+}$cells were seen in the spleens in the Am1010+PBMC and PBMC groups. The number of $\mathrm{CD}^{+}$ cells appeared similar between the two groups. The subtypes of $\mathrm{T}$ lymphocytes were further evaluated by examining CD4, CD8 and FoxP3 immunoreactivity in the spleens. Among these subtypes in the Am1010+PBMC group, there were more $\mathrm{CD} 8^{+}$cells and fewer $\mathrm{CD} 4^{+}$cells. By contrast, there were more $\mathrm{CD}^{+}{ }^{+}$cells and fewer $\mathrm{CD}^{+}$cells in the PBMC group. FoxP3, a specific marker of regulatory T-lymphocytes, was not detected in either of the two groups.

These T-lymphocyte subtypes were further examined using western blotting (Fig. 3B). Consistent with the immunohistochemistry results, the expression of $\mathrm{CD} 3$ was similar between the Am1010+PBMC and PBMC groups. In the Am1010+PBMC group, the CD8 levels were higher $(\mathrm{P}<0.05)$, but the $\mathrm{CD} 4$ levels were lower $(\mathrm{P}<0.05)$, compared with those in the PBMC group. Notably, FoxP3 protein expression was observed in the two groups. The levels of FoxP3 were lower in the Am1010+PBMC group than in the PBMC group. No CD3, $\mathrm{CD} 4, \mathrm{CD} 8$ or FoxP3 protein expression was observed in the Am1010 group, which served as negative control to prove the successful reconstitution of the immune system.

T-lymphocyte recruitment in tumors. We examined whether $\mathrm{T}$ lymphocytes were recruited in the tumor tissues. Firstly, the tumor tissues were examined using $\mathrm{H} \& \mathrm{E}$ staining (Fig. 4A). In the Am1010 group, the tumor cells had similar size and regular arrangement. In the Am1010+PBMC group, the tumor cells were of different sizes. Notably, there were numerous smaller cells surrounding them. The infiltrated smaller cells were analyzed using immunohistochemistry (Fig. 4B); a large quantity of $\mathrm{CD}^{+}$and $\mathrm{CD}^{+}$cells, and a small quantity of $\mathrm{CD}^{+}{ }^{+}$cells were identified. No FoxP $3^{+}$cells were observed. The four T-lymphocyte markers in the tumor tissues were then evaluated using western blotting (Fig. 4C). The results showed that CD3, CD4 and CD8 were present in cells of the Am1010+PBMC group, but not in cells of the Am1010 group. No FoxP3 expression was identified in either of the two groups.

\section{Discussion}

The poor prognosis of lung cancer is largely due to the fact that lung cancer cells are resistant to chemotherapy drugs and metastasis. The underlying mechanisms have been presumed to be closely associated with dysfunction of immune system, although they are yet not elucidated to date $(21,22)$. In the present study, we established a heterotopic lung carcinoma model in NOD/SCID mice using multi-drug-resistant Am1010 cells, which were prepared from human lung adenocarcinoma. In the model, human PBMC transplantation produced a significant inhibitory effect on tumor growth, and was accompanied by numerous $\mathrm{T}$ lymphocytes, particularly $\mathrm{CD} 8^{+}$cells, in the peripheral blood, spleen and tumor tissue. Our results provide direct evidence for the important role of immune reconstitution from PBMCs in lung cancer regression. 
The Am1010 lung carcinoma cell line is resistant to cisplatin, taxol, and gefitinib. The cancer cells grow and form tumors in vivo, when injected into nude mice (5). In the present study, Am1010 lung carcinoma cells were injected into subcutaneous tissues in NOD/SCID mice, successfully inducing heterotopic tumor growth. When fragments of these tumors were inoculated into recipient NOD/SCID mice, they grew rapidly. The results support our hypothesis that Am1010 lung carcinoma cells and tumor fragments are a useful tool for studying lung carcinoma.

The NOD/SCID mouse strain was developed by crossing SCID mice with NOD mice (12). It has been reported that the engraftment levels of human splenocytes and PBMCs in NOD/SCID mice are 5- to 10-fold higher than those in the classical SCID mice $(23,24)$. Consistent with these reports, the present study showed that intraperitoneal injection of human PBMCs into the NOD/SCID mice produced a gradual increase of human $\mathrm{CD} 3$ lymphocytes in the peripheral blood, and the ratio of $\mathrm{CD} 3$ lymphocytes was $\leq 70 \%$ of the original amount at the fourth week. In addition, immunohistochemistry and western blotting revealed the presence of numerous CD3 cells in the spleen. Thus, the data demonstrate that PBMC transplantation successfully induces T-lymphocyte reconstitution in NOD/SCID, not only in the peripheral blood, but also in a lymphoid organ.

Numerous studies have analyzed the association between tumors and immunity. TILs have been widely reported to have protective functions against tumors. TILs have been identified in various types of tumors, including lung cancer. Their existence has been found to be associated with decreased tumor progression (25), induction of responses to chemotherapy $(26,27)$ and increased lifetime of patients $(28)$. TILs derived from neonatal cord blood mononuclear cells induced marked human lung and cervical tumor remission in NOD/SCID mice, and the antitumor effect was accompanied with a high infiltration of $\mathrm{CD}^{+} \mathrm{T}$ cells in tumors and a marked induction of apoptotic cell death (25). In the present study, PBMC engraftment by intraperitoneal injection significantly slowed the lung tumor growth and induced $\mathrm{CD}^{+}$ T-lymphocyte recruitment in tumors. Therefore, the TILs may be an important factor for lung cancer remission in this study.

$\mathrm{T}$ lymphocytes are mainly composed of helper lymphocytes $\left(\mathrm{CD}^{+} \mathrm{T}\right.$ cells), cytotoxic $\mathrm{T}$ lymphocytes (CTLs or $\mathrm{CD} 8^{+}$ $\mathrm{T}$ cells) and regulatory $\mathrm{T}$ cells (FoxP3 ${ }^{+} \mathrm{T}$ cells) (29). A great quantity of animal studies and clinical data has revealed the important role of T-lymphocyte subtypes in antitumor effects $(30,31)$. An investigation of 335 cases of non-small cell lung cancer (NSCLC) showed that an increased number of epithelial $\mathrm{CD}^{+}$, stromal $\mathrm{CD} 8^{+}$and stromal $\mathrm{CD} 4^{+}$lymphocytes was significantly correlated with improved disease-specific survival. In particular, a low level of stromal $\mathrm{CD}^{+}$lymphocyte infiltration was associated with an increased incidence of angiolymphatic invasion (32).

$\mathrm{CD} 8^{+} \mathrm{T}$ cells have been found to be associated with improved outcome in the majority of human tumors (33), including lung cancer $(32,34)$. In the present study, we observed that $\mathrm{T}$ lymphocytes infiltrated into tumors. The T-lymphocyte subtypes were mainly $\mathrm{CD} 8^{+}$lymphocytes. Thus, the $\mathrm{CD} 8^{+}$ lymphocytes from PBMCs may underlie the key protective mechanism against lung cancer progression in this study.
In contrast to $\mathrm{CD} 8^{+}$lymphocytes, infiltration of tumors by regulatory $\mathrm{T}$ cells is instead associated with poor prognosis in NSCLC and other carcinomas (35). The regulatory T cells are thought to function primarily in cancers by repressing $\mathrm{CD}^{+} \mathrm{T}$-cell function. The regulatory T-cell depletion may be therapeutically beneficial (35). In the present study, FoxP3, the marker of regulatory $\mathrm{T}$ cells, was not observed in tumors in immunohistochemistry and western blotting, although FoxP3 protein expression was observed in the spleen. The results suggest that $\mathrm{PBMC}$-inoculated mice may have intact $\mathrm{CD} 8^{+}$ T-cell function, which exerts potent tumor toxicity effect.

In conclusion, in the present study, we applied multi-drug-resistant lung carcinoma cells to explore the protective effect of immune reconstitution from PBMC transplantation. The infiltration of a high proportion of $\mathrm{CD} 8^{+} \mathrm{T}$ lymphocytes, but not regulatory $\mathrm{T}$ lymphocytes, into tumors may underlie the mechanism. To the best of our knowledge, this is the first study involving immunoprotection and multi-drug-resistant lung carcinoma in general. This study may provide a basis for immunotherapy in drug-resistant lung carcinoma.

\section{Acknowledgements}

This study was supported by the National Natural Science Foundation (81000951), the China Postdoctoral Science Foundation (684750) and initial PhD funding by Guangzhou Medical College (2008C3).

\section{References}

1. Jemal A, Siegel R, Ward E, Hao Y, Xu J, Murray T and Thun MJ: Cancer statistics, 2008. CA Cancer J Clin 58: 71-96, 2008.

2. Nadkar A, Pungaliya C, Drake K, Zajac E, Singhal SS and Awasthi S: Therapeutic resistance in lung cancer. Expert Opin Drug Metab Toxicol 2: 753-777, 2006.

3. Levina V, Marrangoni AM, DeMarco R, Gorelik E and Lokshin AE: Drug-selected human lung cancer stem cells: cytokine network, tumorigenic and metastatic properties. PLoS One 3: e3077, 2008.

4. Wang X, Long M, Dong K, Lin F, Weng Y, Ouyang Y, Liu L, Wei J, Chen X, He T and Zhang HZ: Chemotherapy agents-induced immunoresistance in lung cancer cells could be reversed by trop-2 inhibition in vitro and in vivo by interaction with MAPK signaling pathway. Cancer Biol Ther 14: 1123-1132, 2013

5. Li HL, Xie SM, Zhang L, Cai CJ, Wang W, Huang J, Wang DY, Wen DP, Deng QH, Zhong NS and He JX: Establishment and characterization of a new drug surviving cell line Am1010, derived directly from muscle metastases of a human lung adenocarcinoma patient with multi-drug-resistance to cisplatin, taxol, and gefitinib. Acta Pharmacol Sin 31: 601-608, 2010

6. Prestwich RJ, Errington F, Hatfield P, Merrick AE, Ilett EJ, Selby PJ and Melcher AA: The immune system - is it relevant to cancer development, progression and treatment? Clin Oncol (R Coll Radiol) 20: 101-112, 2008.

7. Gooden MJ, de Bock GH, Leffers N, Daemen T and Nijman HW: The prognostic influence of tumour-infiltrating lymphocytes in cancer: a systematic review with meta-analysis. Br J Cancer 105: 93-103, 2011.

8. Sharma P, Shen Y, Wen S, Yamada S, Jungbluth AA, Gnjatic S, Bajorin DF, Reuter VE, Herr H, Old LJ and Sato E: CD8 tumor-infiltrating lymphocytes are predictive of survival in muscle-invasive urothelial carcinoma. Proc Natl Acad Sci USA 104: 3967-3972, 2007.

9. Staibano S, Mascolo M, Tranfa F, Salvatore G, Mignogna C, Bufo $P$, Nugnes L, Bonavolontà G and De Rosa G: Tumor infiltrating lymphocytes in uveal melanoma: a link with clinical behavior? Int J Immunopathol Pharmacol 19: 171-179, 2006. 
10. Nakamura H, Saji H, Ogata A, Hosaka M, Hagiwara M, Kawasaki N, Konaka C and Kato H: Immunologic parameters as significant prognostic factors in lung cancer. Lung Cancer 37: 161-169, 2002.

11. Pelletier MP, Edwardes MD, Michel RP, Halwani F and Morin JE: Prognostic markers in resectable non-small cell lung cancer: a multivariate analysis. Can J Surg 44: 180-188, 2001.

12. Shultz LD, Schweitzer PA, Christianson SW, Gott B, Schweitzer IB, Tennent B, McKenna S, Mobraaten L, Rajan TV, Greiner DL, et al Multiple defects in innate and adaptive immunologic function in NOD/LtSz-scid mice. J Immunol 154: 180-191, 1995.

13. Smit JK, Faber H, Niemantsverdriet M, Baanstra M, Bussink J, Hollema H, van Os RP, Plukker JT and Coppes RP: Prediction of response to radiotherapy in the treatment of esophageal cancer using stem cell markers. Radiother Oncol 107: 434-441, 2013.

14. Yamauchi Y, Izumi Y, Asakura K, Kawai K, Wakui M, Ohmura M, Suematsu M and Nomori H: Lewis lung carcinoma progression is facilitated by TIG-3 fibroblast cells. Anticancer Res 33: 3791-3798, 2013.

15. van der Loo JC, Hanenberg H, Cooper RJ, Luo FY, Lazaridis EN and Williams DA: Nonobese diabetic/severe combined immunodeficiency (NOD/SCID) mouse as a model system to study the engraftment and mobilization of human peripheral blood stem cells. Blood 92: 2556-2570, 1998.

16. Kretz-Rommel A, Qin F, Dakappagari N, Cofiell R, Faas SJ and Bowdish KS: Blockade of CD200 in the presence or absence of antibody effector function: implications for anti-CD200 therapy. J Immunol 180: 699-705, 2008

17. Xu Y, Sun J, Sheard MA, Tran HC, Wan Z, Liu WY, Asgharzadeh S, Sposto R, Wu HW and Seeger RC: Lenalidomide overcomes suppression of human natural killer cell anti-tumor functions by neuroblastoma microenvironment-associated IL-6 and TGF $\beta 1$. Cancer Immunol Immunother 62: 1637-1648, 2013.

18. Perdomo C, Campbell JD, Gerrein J, Tellez CS, Garrison CB, Walser TC, Drizik E, Si H, Gower AC, Vick J, Anderlind C, Jackson GR, Mankus C, Schembri F, O'Hara C, Gomperts BN, Dubinett SM, Hayden P, Belinsky SA, Lenburg ME and Spira A: MicroRNA 4423 is a primate-specific regulator of airway epithelial cell differentiation and lung carcinogenesis. Proc Natl Acad Sci USA 110: 18946-18951, 2013.

19. Maes E, Landuyt B, Mertens I and Schoofs L: Interindividual variation in the proteome of human peripheral blood mononuclear cells. PLoS One 8: e61933, 2013.

20. Dai YQ, Jin DZ, Zhu XZ and Lei DL: Triptolide inhibits COX-2 expression via NF-kappa B pathway in astrocytes. Neurosci Res 55: 154-160, 2006.

21. D'Antonio C, Passaro A, Gori B, Del Signore E, Migliorino MR, Ricciardi S, Fulvi A and de Marinis F: Bone and brain metastasis in lung cancer: recent advances in therapeutic strategies. Ther Adv Med Oncol 6: 101-114, 2014.

22. Wang C, Xiao Q, Li YW, Zhao C, Jia N, Li RL, Cao SS, Cui J, Wang $\mathrm{L}, \mathrm{Wu}$ Y and Wen AD: Regulatory mechanisms of annexin-induced chemotherapy resistance in cisplatin resistant lung adenocarcinoma. Asian Pac J Cancer Prev 15: 3191-3194, 2014.
23. Greiner DL, Shultz LD, Yates J, Appel MC, Perdrizet G, Hesselton RM, Schweitzer I, Beamer WG, Shultz KL, Pelsue SC, et al: Improved engraftment of human spleen cells in NOD/LtSz-scid/scid mice as compared with C.B-17-scid/scid mice. Am J Pathol 146: 888-902, 1995.

24. Hesselton RM, Greiner DL, Mordes JP, Rajan TV, Sullivan JL and Shultz LD: High levels of human peripheral blood mononuclear cell engraftment and enhanced susceptibility to human immunodeficiency virus type 1 infection in NOD/LtSz-scid/scid mice. J Infect Dis 172: 974-982, 1995.

25. Lee YS, Kim TS and Kim DK: T lymphocytes derived from human cord blood provide effective antitumor immunotherapy against a human tumor. BMC Cancer 11: 225, 2011.

26. Liu H, Zhang T, Ye J, Li H, Huang J, Li X, Wu B, Huang X and Hou J: Tumor-infiltrating lymphocytes predict response to chemotherapy in patients with advance non-small cell lung cancer. Cancer Immunol Immunother 61: 1849-1856, 2012.

27. Morris M, Platell C and Iacopetta B: Tumor-infiltrating lymphocytes and perforation in colon cancer predict positive response to 5-fluorouracil chemotherapy. Clin Cancer Res 14: 1413-1417, 2008

28. Lee WS, Kang M, Baek JH, Lee JI and Ha SY: Clinical impact of tumor-infiltrating lymphocytes for survival in curatively resected stage IV colon cancer with isolated liver or lung metastasis. Ann Surg Oncol 20: 697-702, 2013.

29. Batchelder CA, Duru N, Lee CI, Baker CA, Swainson L, Mccune JM and Tarantal AF: Myeloid-lymphoid ontogeny in the rhesus monkey (Macaca mulatta). Anat Rec (Hoboken): May 28, 2014 (Epub ahead of print)

30. Fearon ER, Pardoll DM, Itaya T, Golumbek P, Levitsky HI, Simons JW, Karasuyama H, Vogelstein B and Frost P: Interleukin-2 production by tumor cells bypasses $\mathrm{T}$ helper function in the generation of an antitumor response. Cell 60: 397-403, 1990.

31. Rosenberg SA: A new era for cancer immunotherapy based on the genes that encode cancer antigens. Immunity 10: 281-287, 1999.

32. Al-Shibli KI, Donnem T, Al-Saad S, Persson M, Bremnes RM and Busund LT: Prognostic effect of epithelial and stromal lymphocyte infiltration in non-small cell lung cancer. Clin Cancer Res 14: 5220-5227, 2008.

33. Fridman WH, Pagès F, Sautès-Fridman $C$ and Galon J: The immune contexture in human tumours: impact on clinical outcome. Nat Rev Cancer 12: 298-306, 2012.

34. Donnem T, Al-Shibli K, Andersen S, Al-Saad S, Busund LT and Bremnes RM: Combination of low vascular endothelial growth factor A (VEGF-A)/VEGF receptor 2 expression and high lymphocyte infiltration is a strong and independent favorable prognostic factor in patients with nonsmall cell lung cancer. Cancer 116: 4318-4325, 2010

35. Ganesan AP, Johansson M, Ruffell B, Beltran A, Lau J, Jablons DM and Coussens LM: Tumor-infiltrating regulatory $\mathrm{T}$ cells inhibit endogenous cytotoxic $\mathrm{T}$ cell responses to lung adenocarcinoma. J Immunol 191: 2009-2017, 2013. 